\title{
DIE VRYMESSELARY TEOLOGIES BEOORDEEL
}

'n Teologiese beoordeling van Vrymesselary beteken om hierdie or. ganisasie, sy grondslae, beginsels en doelstellings krities te besien in die lig van die absolute waarheid in Christus. Vanselfsprekend sal $d^{\prime} t$ dus vir ons primêr gaan om 'n kritiese behandeling van die opvatting en uitsprake van hierdie organisasie oor God Drie-enig, sy houding teenoor kerk en godsdiens, sy Skrifbeskouing, sy siening van die mens, sy toekomsverwagting e.d.m. Aangesien ons in die Vrymesselary te doen het met ' $n$ organisasie wat van sy lede 'n plegtige onderneming eis om sekere geheime en geheimenisse te ,heal and conceal" en niks daarvan op enige wyse tot die kennis van oningewydes te laat kom nie, is dit te verwagte dat daar in die literatuur oor die Vrymesselary - en ook van Vrymesselaars self - baie onvoldoende gemotiveerde uitsprake gevind sal word. Die meeste outertieke Vrymesselaars-outeurs verseker ons egter dat Vrymesselary geen geheime organisasie is nie en dat hulle beginsels en doelstellings algemeen bekend is. Ons wil ons beoordeling van hierdie organisasie dan ook beperk tot daardie uitsprake wat min of meer algemeen aanvaar word as uitdrukking van die ware prinsiepes en doelstellings van die Vrymesselary.

Om enige beweging, en dus ook 'n organisasie soos die Vrymesselary te leer ken en verstaan, is dit goed om die geestelike bodem en klimaat te ontdek waaruit hy opgeskiet en aanvanklik gegroei het. So ontdek 'n mens gewoonlik die basiese struktuur van 'n organisasie, sy onveranderlike organiserende prinsiep, ondanks die modifikasies wat die uiterlike vorm en gestalte in die loop van jare mag ondergaan. Die moderne teoretiese of spekulatiewe Vrymesselary, het sy historiese bestaan gekry met die stigting van die Londonse Groot Losie in 1717. Later het nog drie ander Groot Losies ontstaan: 'n Skotse, 'n Ierse en 'n Vastelandse, bekend as die Groot Losie van die Ooste. Hierdie groot Losies erken mekaar wedersyds, 
hoewel elkeen 'n eie konstitusie het. En alhoewel daar variasie is in simboliek en rituëel, stem hulle wesenlik met mekaar ooreen. Wat die sentrale idee betref, het ons dus met 'n wêreldorganisasie te doen, maar nie wat die organisatoriese betref nie. Uit hierdie vier Groot Losies het talle plaaslike losies of werkplekke ontstaan oor byna die hele wêreld. (Tussen hakies moet ons hier opmerk dat daar onlangs in Suid-Afrika sterk vertoë gerig is deur vooraanstaande Vrymesselaars tot die Vrymesselaarsoutoriteite met die oog op die stigting van 'n Suid-Afrikaanse Groot Losie. Die rede daarvoor is om die ritueel e.a. 'n meer Afrikaanse karakter te gee om teenkanting van die kant van Afrikaners en veral van die Afrikaanse kerke onskadelik te maak. Intussen het 'n Suid. Afrikaanse Orde van Vrymesselaars ontstaan, met baie Afrikaanssprekende lede, maar hierdie organisasie word nie deur die vier ander ordes erken nie.)

Sowel die tyd as die plek van ontstaan van die moderne Vrymesselary is van betekenis. Die jaar 1717 verplaas ons in die tyd toe die Aufklärungswinde van verandering die Europese geestelike- en geesteslewe diepgrondig verander het. 'n Ander mens met 'n ander lewensbeskouing is gevorm met sy mees uitstaande karakteristiek die ontkenning van enige binding aan wat met Bybel en kerk uitgedruk word. As ons slegs enkele tendense van die Aufklärung moet aandui, kan ons stel dat dit die tyd was van die ontwaking van die persoonlikheid en sy selfstandigheid teenoor die kerk. Dit was die begin van die verbluffende resultate op die gebied van die natuurwetenskaplike ondersoek waaruit die krag van die menslike verstand onomstootlik geblyk het. Die mens met sy verstand, intelektualisme, rasionalisme het die middelpunt van alles ingeneem en die mens self het die maat van alle dinge geword. Hierdie tyd van verligting en van bevryding van die menslike gees en verstand het 'n wye kennishorison geopen, en die resultate van natuurwetenskaplike ondersoek het die mens van hierdie tyd vervul met 'n optimistiese vooruitgangsgeloof.

Die gees van die nuwe tyd het ook nadelig ingewerk op kerk en teologie. Ons wil nie die teologie van hierdie tyd breedvoerig bespreek nie, maar slegs enkele aspekte navore bring. Eerstens moes die Reformatoriese Skrifbeskouing en openbaringsopvatting plek maak vir 'n rasionalisties Skrif- en openbaringsleer. Die lewende geloof het verstar tot 'n paar objektiewe waarhede wat verstandelik aanvaar is. In die teologie het die openbaring in Bybelse sin plek gemak vir filosofiese besinning op verskynsel van die godsdiens. Die algemene opvatting was dat daar een algemene natuurlike ideale godsdiens is, waarvan die verskillende historiese godsdienste slegs individuele uitingsvorme is. Ook die christelike geloof is maar net 'n bepaalde konkretisering van die algemene idee van die godsdiens. In die 19de eeuse teologie het dit daartoe gelei dat Christus maar net as godsdiensstigter of as uitstaande religieuse persoonlikheid ge- 
waardeer is wat vir ons die groot voorbeeld van sedelike trou en god:dienstigheid is. Emil Brunner sê dan ook tereg dat daar van die Bybelse openbaringsgeloof niks anders oorgebly het as 'n paar abstrak-swewende idees nie: die idee van God, vryheid en onsterflikheid. By Lessing het die laaste klein ressie van die Bybels-Reformatoriese openbaringsopvatting 'n plek gevind in sy leer van die geleidelike opvoeding van die menslike geslag. Ten slotte moet ons die aandag daarop vestig dat die neutralisme 'n fundamentele plek inneem in die Aufklärungsdenke. Dit was die tyd waarin die Stoïsynse wysbegeerte met sy oorheersende etiese inslag herleef het. Die natuur of rede wat as die goddelike in die mens angesien is, word die kritiese norm en die grond vir godsdiens en moraal. Maar genoeg oor die tyd waarin die Vrymesselary ontstaan het.

Wat die ontstaanplek betref, London in Engeland, word ons geplaas in 'n land waar die Aufklärung 'n bepaalde gestalte aangeneem het. $\mathrm{Na}$ die lange en soms bittere konfessionele stryd, was daar in Engeland 'n groeiende behoefte aan die beëindiging van alle godsdienstige teëstellings. Die Aufklärungsgedagte het hier in Engeland sy bepaalde gestalte gekry in die Engelse Deïsme. Die natuurlike godsdiens, gegrond op 'n rasionalis. tiese openbaringsbegrip was die grondgedagte van die Deïste en hulle het hulleself graag die vrydenkers genoem.

Alles wat nie redelik aanvaarbaar was nie is as ondeugdelik verwerp. Daarom is die leerstellings van die inkarnasie en die triniteit ook afgewys en die hele natuurlike godsdiensbeskouing het neergekom op 'n spekulatiewe beskouing oor God en op 'n naturalisties geöriënteerde etiek.

In die begin van die $18 \mathrm{de}$ eeu het die kerk in Engeland in 'n groot verval verkeer. Vir die toplaag was die kerk verstarde en niksseggende formalisme, vir die middelklas 'n saak van totale onverskilligheid, en die onderste lae is deur geen kerklike invloed bereik nie. Dis in hierdie tyd dat die Vrymesselary opkom as 'n organisasie vir humaniteit en broederlikheid, en wat in die 18 de eeu sy bloeityd beleef het. Daar is mense wat die ontstaan van Vrymesselary wil sien as reaksie en protes teen die gees van die tyd en 'n poging om dit te oorwin. So betoog G. Schenkel in 'n artikel in RGG dat dit 'n protes was teen die Middeleeuse absoluutheidsaanspraak van die Christendom en teen die konfessionele strengheid in die Na-Reformatoriese tyd waardeur die evangelie van die God van liefde ongeloofwaardig gemaak is. $\mathrm{Hy}$ gaan sover as om te beweer dat dit nie uit ongodsdienstigheid is nie, maar uit 'n godsdienstigheid van hoër orde dat die protes van die Vrymesselary teen 'n ontaarde christendom gekom het. Wat presies bedoel word met godsdienstigheid van 'n hoër orde, is nie duidelik nie. Uit die uitsprake oor die plek en betekenis van die godsdiens in die Vrymesselary blyk in elk geval nie veel van die hoër orde nie, soos straks aangetoon sal word. Veeleer is 'n geleidelike 
verwatering van die christelike godsdiens opmerklik en uiteindelik 'n ontkenning van sy besondere betekenis. Bowendien verseker Vrymesselaarsoutoriteite ons uitdruklik dat hierdie organisasie geen godsdiens wil wee: nie en derhalwe seker nie baie geesdrif vir godsdienstige hervorming aan die dag sal lê nie. En indien dit 'n reaksie teen die gees van die tyd was, moet ons konstateer dat die resultaat uiters power en in die geheel nie geslaagd was nie, aangesien die grondgedagtes van daardie tyd soos wat ons dit kortliks hierbo geskets het onbelemmerd voortgeleef het in die Vrymesselary en sy doelstellings, soos ons nou verder wil aantoon.

Die eerste vraag wat ek wil stel is of ons in die Vrymesselary met in godsdiens te doen het. Die meeste skrywers teen die Vrymesselary van christelike kant antwoord hierdie vraag ondubbelsinnig bevestigend, en wil Vrymesselary as die uiterste vorm van sinkretisme sien. Persoonlik kan ek nie die organisasie met so 'n hoogklinkende naam versier nic. Sy ekwiwalent in die godsdiensgeskiedenis en -fenomenologie sal ek veeleer wil soek in 'n sekte of nog eerder in ' $n$ vereniging of geheime bond waarin godsdienstige elemente ook 'n rol speel. Eerder as om Vrymesselary 'n godsdiens in die gewone sin te noem, sal ek hom wil beskrywe as 'n geheime humanistiese-moralistiese broederskap waarin 'n uitgebreide en seremoniëel, met elemente uit byna alle godsdienste van die hede en die verlede, "n sentrale plek inneem. Dis dus meer 'n morele sisteem en van elkeen wat toetree word gevra om die heilige pligte van die moraliteit te beoefen. In die ,Masonic Journal' van 1923 sê 'n bekende vrymesselaar die volgende van sy organisasie: „We are really a society of benevolent Moralists who use a symbolic ritual with devotional, instructive and beautiful ceremonies whose origin is traced to the ancient mysteries". Ons wil die bewering dat die Vrymesselary 'n humanisties-moralistiese broeder. skap is nou verder substansiëer. Die humanisme het eerbied en waardering vir alles wat menslik is en glo aan die waarde en die waardigheid van die mens en die mensheid. En as sodanig kan ons teen so 'n opvatting seker geen beswaar hê nie. Maar daarmee is nie alles omtrent die huma. nisme gesê nie. Dit word heeltemal 'n ander saak as die mens of die mensheid losgemaak word van God en as 'n selfstandige, outonome groo:heid naas God gestel word met eiemagtige potensialiteite sonder enige binding aan iemand bo hom. Dan word die mens die maat van alle dinge en dra hy alle maatstawwe en norme in homself. Dit beteken dat die mens die waarheid in homself besit en dat hy direkte, onmiddelbare toegang daartoe het deur veral die verligting van sy rede. In sy diepste innerlike is die mens dus identies met die absolute of goddelike. In sy eie diepte kan hy ook die sin en bestemming van die mens en die mensheid ontdek en in die krag van sy rede en wil besit hy ook die vermoë om daardie bestemming te verwesenlik. Soos agter elke, ,isme" lê ook agter die Humanisme 'n geloof wat 'n deel tot die geheel verhef, iets relatiefs tot iets absoluuts, en die oorgawe aan daardie absolute. As sodanig het 
ons dus te doen met 'n subtiele kreatuurvergoding en moet die humanisme as ' $n$ afgod bestry word.

Dat hierdie humanisties-moralistiese denke die wese van die Vry' messelary uitmaak, kan met oorvloedige bewyse gestaaf word. Ons wil enkeles aanstip en begin waar 'n Vrymesselaar deur inlywing of inisiasie toegelaat word tot die ,craft". Hierdie inlywing of inisiasie word deur Vrymesselaars beskou as 'n seremonie wat aan kerklike gebruik ontleen is, en die ekwiwalent van die heilige doop is. "The Church Fathers in their homilies commonly refer to the baptized brethern as "the initiated" ". (B. E. Jones, The Freemason's Guide and Compendium, 258). Die eerste intrede van 'n kandidaat in 'n masonieke tempel gaan gepaard met allerlei ou gebruike, waarin o.a. ook 'n sterk Joodse invloed te bespeur is. Deur die eeue was dit die gebruik by die inlywing in misteries, en so ook t.o.v. die geheimenisse van die Vrymesselary, dat 'n kandidaat geblinddoek binnegelei word. Die blinddoek is nie alleen 'n embleem van geheimhouding nie. maar van die duisternis waarin die kandidaat verkeer en wat verdwyn met sy inisiasie. (Jones 268). Sy fisieke duisternis is simbool van sy geestelike onkunde. So 'n kandidaat kom as 't ware slordig gekleed die tempel binne. Sy klere is los, so ook sy skoene en dikwels is die een voet sonder skoen. Die skoen word dan verklaar as afwering van gevaar, die gevaar nl. dat die kandidaat dalk nie weergebore mag word tot 'n staat van ware verligting nie. Daar is nog ander simbole en seremonies soos gebruiklik by die Losies van Engelse konstitusies, waarop ons in 'n ander verband later sal terugkom. Ons wil dieselfde inlywingsseremonie kortliks skets soos gebruiklik by die Orde van die Groot Ooste. Ook daar word die kandidaat geblinddoek binnegelei en na 'n derde sinnebeeldige reis in die tempel, word die lig van die orde aan hom geskenk. Nou is die broer in die leerlinggraad, 'n graad waarin die geskenkte lig reinigend moet dring in die binneste tot ware selfkennis. Dan word die broer verhef tot die tweede of Metgeselgraad wat weer 'n eie seremoniëel het In die kamer van voorbereiding, makk hy kennis met allerlei spreuke soos ontwikkel u gees en $\mathrm{u}$ hart, sodat dit die saad van die wysheid en ware „,vriendskap kan opneem en laat groei tot skone wasdom”. By sy intrede in die tempel is die eerste teken wat opval die vlammende ster in die Ooste met die letter "G". Hierdie simbool word verskillend verklaar. By sommige is dit "God the Grand Geometrician of the Universe" maar dit kan ook staan vir ,gnosis" en wil herinner aan die juiste gebruik van die verstand. Dit moet ook vir ander skyn, die profanes, tot oefening in verligting, veredeling en volmaking. Wanneer die leerling tot Metgesel Vrymesselaar verhef word, bestaan 'n deel van die seremonie uit die makk van vyf denkbeeldige reise waarby verskillende instrumente gedra word: die hamer en beitel is simbool van die vorming van mense tot passende kubusstene in die groot tempel van die mensheid. Alle punte wat die harrronie kan versteur moet weggekap word. Die passer is simbool 
van die wêreldomvattende terrein waarbinne gewerk moet word aan die heil van die mensheid, verstandelik en sedelik. So is die koevoet simbool van die verwydering van alle hindernisse in die mensheid tot aanvaarding van die beginsels van die Vrymesselary. En die belangrikste van die hindernisse wat verwyder moet word, waarvan die winkelhak simbool is, is die verskil in stand en staat, kerkleer, vooroordele deur geboorte, opvoeding en kerkgeloof. 'n Goeie arbeider aan die heil van die mensheid is dus hy wie se verstand so verlig is dat hy alle vooroordele kan afskud en al sy dade meet na die mat van die suiwere en gesonde rede. Die Vrymesselaar is die kampioen vir vooruitgang en verligting, die dokter wat die kanker uit die maatskappy wil uitroei. En in die uitvoering van sy taak staar hy op die vlammende ster en hy glo in die eindelose volmaaktheid van die mensenatuur, en dat eenmaal die gebou waaraan hy meegewerk het geheel voltooi sal wees. In poëtiese taal klink dit dan:

„Rys op dan, schoon gebouw van braafheid en verstand.

En altyd duren zult, wat wank'len moog of zinken ..

Gy reest door Wysheid en gy staat door eigen Kracht".

Uit die geheel van die bogaande, wat geneem is uit 'n ou Vrymes' selaargids aan die einde van die $19 \mathrm{de}$ eeu, het dit al duidelik geword watter taak die Vrymesselary hom ten doel stel in die wêreld: nl. die sedelike opvoeding, ontwikkeling, verbetering, veredeling en vervolmaking van die mensheid. Eerstens moet deur die lig wat die Vrymesselary skenk die eie verbetering, veredeling en vervolmaking nagejaag word om dan tot heil van die hele mensheid te werk. Die heel eerste artikel van die Wetboek van die Orde van die Groot Ooste, stel die doel van Vrymesselary dan ook kort en bondig: Het Menschdom beter te doen worden. In allerlei mooi variasies kom hierdie grondgedagte telkens weer terug in Vrymesse. laarsgeskrifte en toesprake: dit gaan om stryd teen en oorwinning van duisternis, vooroordeel en bekrompenheid, stryd vir ontwikkeling, verbetering, veredeling van die mensheid. Dis dan ook geen wonder dat die vrymesselary wat hom so uitsluitlik rig op die verbetering van die mensheid, op die verspreiding van „charity" en ,goodwill" in die wêreld, op die verwydering van die kankers in die matskappy, so 'n geweldige aanhang het in die land by uitstek van die social gospel, Amerika nie.

Maar dis nie net klanke uit 'n ver verlede en uit 'n ver land nie. hulle klink ook in ons onmiddellike omgewing. Die Voorsittende Meester van die Losie „,De Broederband" in Pretoria, skryf in sy jaarverslag 1951/ 52: „Soos in die verlede het ons ook hierdie jaar ons kwota gehad van Broers wat moeg geword het van die nyd, jaloesie en afguns wat in die buitewêreld heers en hulle toevlug geneem het tot ons Heilige Orde om daar die Broederskap en veredeling van gees en hart te soek wat maar nouliks in die profane wêreld te vinde is". En dan spreek hy die wens uit dat die Masonieke saad wat met soveel erns gesaai is, wortel mag skiet in 
die harte van die broers tot seën en heil nie net vir hulleself nie, maar ook vir almal met wie hulle in aanraking kom. En met die stigting en wyding van die eerste Afrikaanse Losie onder die Skotse Konstitusie in Augustus 1951, sê die hoofspreker van die aand, as hy dit het oor waarvoor Vrymesselary staan - nadat hy gewys het op die verdraag. saamheid teenoor en op die gelykheid van alle tale, nasies, rasse en kleure in die Vrymesselaarsgeledere, solank hulle maar "good men and true" is, en gehoorsaam is aan die morele wet dat daar ' $n$ universele behoefte is aan broederskap van alle mense wat "goodwill", vrede en harmonie sal bevorder en bevestig. Dis vir so 'n broederskap dat die Vrymesselary staan en wanneer broederskap en liefdadigheid die hele wêreld omsluit, ,then indeed will the true spirit of Freemasonry prevail, and humanity be well on its way to ultimate perfection". Vrymesselaars word dan ook oral opgeroep om die waarheid wat hulle besit gestalte te laat neem in hulle lewe en gedrag, om so die „superior excellence" van hulle geloof te demonstreer.

Voordat ons oorgaan tot kritiek, nog enkele opmerkings oor die Vrymesselaarsbeskouings t.o.v.

\section{God en die Godsdiens.}

In die dae van die operatiewe Vrymesselary is van 'n Vrymesselaar verwag om eerstens God lief te hê en die heilige kerk en al die heil'ges. Later moes hulle slegs manne wees wat getrou is aan God en die heilige kerk, dus lidmaatskap net vir kerkmense. In die Konstitusie van Anderson in 1723, word die voorgaande vervang as in die eis betreffende God en die godsdiens die volgende gestel word: dit word nou wensliker geag om hulle alleen te verplig tot daardie godsdiens waarin alle mense saamstem, terwyl hulle afsonderlike opinies aan hulleself oorgelaat word. Maar dan gaan hy verder en sê: die volgende ding waaraan ek julle wil herinner is om politiek en godsdiens te vermy, ,any association with them as a Society, for our politics is merely to be honest and our Religion the Law of Nature, and to love God above all things and our Neighbour as ourself". Dit volgens hom is die katolieke en universele godsdiens wat ten alle tye erken is. Die „Law of Nature” is dus die eintlike waarom dit gaan, en daarna die liefde tot God en naaste. Die ou pligte van 'n Vrymesselaar wat as inleiding by elke Konstitusie van die Verenigde Groot Losie van Engeland (1813) opgeneem word, begin sy eerste artikel onder die hoof: Omtrent God en Godsdiens, so: „A mason is obliged, by his tenure, to obey the moral law . . . let a man's religion and mode of worship be what it may, he is not excluded from the order, provided he believes in the glorious architect of heaven and earth, and practise the sacred duties of morality". Dis weer opvallend dat die uitspraak begin en eindig met die klem op die morele pligte. Jones sê in sy reeds genoemde werk dat 'n kandidaat geregtig is om enige godsdienstige beginsel 
of geloof te huldig, en hy sal gerespekteer word ,as long as he brings into freemasonry just one all-essential part of his code - a belief in the Glorious Architect of heaven and earth". Dit dan is die naam van die God van die Vrymesselary op wie elke Vrymesselaar sy vertroue moet stel, of hy nou christen, Moor of Indiaan, Moslim of Hindhoe is. Dit is 'n gelykstelling van die Heilige van Israel met Baäl, 'n ontkenning van die enigheid van die God van die Bybel. Die deurlugtige argitek van hemel en aarde, die Groot Meetkundige, soos Hy elders genoem word, is nie die Skepperheer van die Bybel nie. Hy is die Deïsties-unitariese, rasionalisties-spekulatiewe, abstrak-onpersoonlike God van die $18 \mathrm{de}$ eeuse denke.

Ook die godsdiensbeskouing vertoon die trekke van die 18de eeuse denke waarvolgens daar een algemene natuurlike godsdiens is, waarvan die historiese godsdienste slegs individuele uitings is wat kwalitatief nie van mekaar verskil nie. Daar is maar een algemene idee of wese van die godsdiens wat verskillende gestaltes in die geskiedenis aanneem. So 'n godsdiensbeskouing lei altyd tot relatiwisme en tot goedkoop verdraagsaamheid met weining bekommernis oor die waarheid. Dis onnodig om te sê dat die christendom nooit sonder geweldpleging en verdraaiing van sy werklike inhoud in so 'n godsdiensopvatting ingeforseer kan word nie.

\section{Jesus Christus.}

Soos wel te wagte kan wees sal in so 'n relatiwistiese en tolerante atmosfeer as wat ons nou net geskets het, weinig plek wees vir Hom wat in persoon die weg, die waarheid en die lewe is. In sy klein geskriffie „Waarom ek die Vrymesselary verlaat het", skryf George C. Schmidt o.a. die volgende: „Om God te aanbid in formuliere wat Jesus Christus verwerp en om opsetlik Sy naam weg te laat, is 'n daad van goddelose afval waarvoor geen verstandelike voorbehoude kan vergoed nie". En waar Jesus Christus wel genoem word is dit net toevallig in verband met simboliek en ritueel. So b.v. word volgens 'n legende die akasia takkie wat by die begrafnisseremoniëel as simbool van onsterflikheid gebruik word, in verband gebring met die kruis en die kroon van dorings. En dan is daar in die derde Vrymesselaarsgraad ook nog die sg. legende en rituëel van Hiram, waar die vrymesselaar simbolies sterf en weer lewendig word. En hoewel dit met 'n gebruik in die ou misteriegodsdienste kan ooreenstem, of in verband gebring kan word met die ste:wende en herlewende natuur, is daar sommige wat dit ook in verband wil bring met die kruis en opstanding van Christus. Hier is in elke geval geen sprake van geloof in Hom wat die opstanding en die lewe is nie, maar die grondgedagte is die heidense onsterflikheidsgedagte, en Christus word slegs toevallig gebruik om kleur en $\mathrm{krag}$ aan 'n simboliese uitbeelding daarvan te gee. 


\section{Die Heilige Skrif.}

Wel is die Bybel in byna elke losie, en met die hand op die Bybel lê elke Vrymesselaar die plegtige eed af om die geheime van die organisasie te bewaar, en wel word hy ook gebruik, saam met ander menslike geskrifte uit die verlede tot versiering van seremonies en tot interpretasie van sim. boliek, maar wat sy boodskap betref is hy 'n geslote boek, niks meer as 'n simbool in die losie nie. Miskien kan wat in die „Jaarboekje voor Nederlandsche Vrymetselaren" deur ene D. Burger gesê word oor die betekenis van die Bybel, as algemene gangbare opvatting geld. Hy sê dat hoewel die Bybel sy waarde verloor het deurdat die literêre kritiek die letterlike inspirasieleer vernietig het, hy tog nie sonder enige waarde is nie. Daar is b.v. baie digterlike skoonheid in en 'n menigte wysgerige denkbeelde wat des te merkwaardiger is omdat die Bybelskrywers nie baie logika en grammatika geken het nie. Die Gelykenisse bevat 'n diepte van mensekennis en 'n wysgerige sedekunde soos wat nergens beter aan te tref is nie. Dit pas die Vrymesselaar om dit alles in ere te hou, omdat en hier lê die angel - hy sy sedelike bewussyn het as toetsteen vir alles wat uit die voortyd oorgelewer is. $\mathrm{Hy}$ besit dus ' $\mathrm{n}$ immanente kriterium vir wat aanneembaar is in die Heilige Skrif.

Daar is nog baie ander aspekte i.v.m. die Vrymesselary wat behandel kan word, maar die behandeldes is genoegsaam om aan te toon wat dic grondslag, gees en doelstellings van hierdie organisasie is. Dis seker nie nodig om baie bewyse aan te voer dat die humanisties-moralistiese grond. gedagte wat ons in die Vrymesselary gevind het 'n ontkenning en ondergrawing is van die Reformatoriese geloofsgetuienis nie. Dis eerstens in stryd met die mees fundamentele Reformatoriese beginsel: die „sola gratia”, die belydenis dat die heil en redding van die mens 'n gawe van Gods vrymagtige genade in Jesus Christus is. Die mens beskik oor geen selfstandige besit of vermoë wat hy tot redding en heil van homself of van die mensheid kan aanwend nie, nog in sy verligte verstand, nog in sy sedelike wil, of in enige ander moontlike menslike kwaliteit nie. Dis alleen God wat red en verlos in Christus en deur die Heilige Gees, en as die mens op watter wyse dan ook homself so 'n reg toeëien, beteken dit dat hy vir homself toeëien wat alleen aan God toekom, en daarmee die eer van God aanrand. Aan die Drie-enige God alleen moet alle eer toegebring word, dit is die noodwendige keersy van die sola gratia. Maar die humanistiese moralisme tas ook die Reformatoriese Skrifprinsiep aan in soverre die grond en norm vir alle geloof en lewe, nie meer die Heilige Skrif is nie, maar 'n immanente wet, die sedelike bewussyn, die menslike rede, wat nou die plek van die Godswoord inneem. En ten derde is die aangeduide opvatting ' $n$ ontkenning en ondergrawing van die Reformatoriese regverdigingsleer, $n$ l. die regverdiging van die goddelose. Die diepste wese van die mens is nie goed nie en ook nie in besit van die 
waarheid nie, maar dis verdorwe deur die sonde. Daarom is die vrolike ontwikkelingsoptimisme van die Vrymesselary met sy verwagting van 'n cdele en volmaakte mensheid, niks anders as 'n skim en ydele droom nie.

'n Laaste vraag wat nou nog op beantwoording wag het betrekking op die houding van die kerk teenoor hierdie organisasie as sodanig, en teenoor sy eie lidmate wat daaraan behoort. Die eerste vraag is seker makliker te beantwoord as die tweede. Want gesien die feit dat die Vrymesselary in sy wese en oogmerk in stryd is met, en gevolglik 'n ondergrawing beteken van die grondbeginsels van ons protestants-christe. like geloof, kan die kerk seker nie anders as om sterk afwysend teenoor hierdie organisasie te staan nie. Die kerk sal seker sy plig versuim as hy nie 'n duidelike en ernstige waarskuwende stem laat hoor teen lid. maatskap van hierdie organisasie. Die kerk immers het die taak om die geeste op die proef te stel, of hulle uit God is, 1 Joh. 4:1. En gesien die uitgangspunt van hierdie organisasie, $\mathrm{nl}$. in die mens self met sy verstandelike en morele $\mathrm{krag}$, en gesien die plek wat aan Jesus Christus toegeken word, ondanks die vryheid wat aan individuele christene gelaat word t.o.v. hulle geloof, het ons her te doen met 'n gees wat nie uit God is nie. Vir my is dit duidelik dat die wese van hierdie organisasie 'n teken is wat in verband staan met die groot afval van die laaste dae waarteen gewaarsku moet word en waarteen die gemeente wat die Heer verwag, moet stry. Hierdie organisasie, sy gees, (en dan dink ek nie aan individuele lede nie) is des te gevaarliker as ons hom sien in die kader van hierdie gesekulariseerde tyd waarin ons lewe, soms ook die na-chris. telike tyd genoem, waarin daar nee gesê word aan Christus die Heer van die wêreld.

Wat die houding van die kerk moet wees teenoor sy eie lidmate wat aan hierdie organisasie behoort, is 'n vraag wat seker moeiliker te beantwoord is en wat baie ernstige nadenke verg. Graag wil ek enkele riglyne aanbied vir wat dit werd is. 'n Mens kan jou alleen maar verbaas en dit beswaarlik glo dat ' $n$ belydende lidmaat wat gedoop is in die Naam van Hom wat die lig van die wêreld is, wat onderrig is in die leer van die Kerk t.o.v. die Drie-eenheid, sonde en genade, wat in die gemeenskap van die kerk in hoogste verbondenheid met God en sy medemens lewe, wat in Christus die alleen ware vrede en vreugde besit, wat binne die kerk beter as elders die wêreld kan dien - dat so 'n lidmaat, simbolies arm en in duisternis - lig vir sy lewe en vir die wêreld sal gaan afsmeek by 'n organisasie soos hierdie. Dit kan alleen uit matelose onkunde en deur 'n skreiende gebrek aan onderskeidingsvermoë geskied.

En nou moet 'n ander saak my ook van die hart af. Berkhof het iewers gesê dat God nie net deur die kerk tot die wêreld spreek nie. maar ook deur die wêreld tot die kerk. Kom daar nie dalk ook van die kant van die bestaan van 'n organisasie soos die Vrymesselary 'n vraag 
na die kerk toe nie: het u nie dalk skuld daaraan nie? Het die kerk nie eeue lank miskien te veel na binne gelewe nie, en die vreugdelose bestaan van die wêreld, die skreiende nood van die mensheid uit die oog verloor nie? Het die kerk in die verlede sy volle ernstige aandag gegee aan die suiwere Woordverkondiging en so die wêreldgerigte evangelie in en aan die wêreld bedien? En doen hy dit vandag? Het die kerk sy volle onverdeelde aandag gegee aan sy primêre taak om deur prediking, woordgebonde sielsorg en doeltreffende kategetiese onderrig sy lidmate toe te rus vir hulle diens. werk tot opbouing van die liggaam van Christus? En doen hy dit vandag? Moet ' $n$ mens jou nie telkens weer verbaas oor die weerloosheid van die deursnee lidmaat van die kerk teenoor allerlei valse leringe waarmee hulle byna daagliks te doen kry nie? Met die oog op al hierdie dinge wil ek pleit vir geduld en bewoënheid met, vir simpatieke begrip, liefdevolle tereg. wysing en insiggewende onderrig van hulle wat "verval" het tot lidmaatskap van 'n organisasie met ' $n$ vreemde gees. Laat ons nie vergeet nie, dat daar in die vorige eeu eminente figure in die kerk was wat teologiese opvattings gehuldig het wat wesenlik ooreenstem met die grondgedagtes van die Vrymesselary - hoewel hulle christene was en geen Vrymesselaarslede nie. En as dit met die groen hout gebeur het, wat moet van die droë hout word?

F. J. VAN ZYL 